\title{
Tax-Free Transit Benefits at 30: Evolution of a Free Parking Offset
}

\author{
Stuart M. Baker, Stuart M. Baker, Inc. \\ David Judd, Transportation Consultant \\ Richard L. Oram, Oram Associates, Inc.
}

\begin{abstract}
Tax-free employee transit benefits emerged in the 1970s along with monthly pass plans and evolved over a 30-year period to be an important part of transit marketing, transit revenue, and traffic mitigation strategies. Transit benefit plans succeeded partly because they are an "offset" to employer-provided tax-free parking, an integral part of transit's market context in theoretical and practical terms. First authorized in 1984 at a tax-free monthly maximum of $\$ 15$, transit benefit legislation was expanded numerous times and now allows a monthly maximum of $\$ 230$, equaling tax-free parking. Indicating the effectiveness of workplace market development, transit benefit impacts greatly exceed what comparable changes in transit fare levels suggest. A series of innovations for delivering transit benefits and unique public-private relationships provided ever-better ways to meet employer needs, and will continue to evolve as transit fare collection methods advance.
\end{abstract}

\section{Introduction}

This paper summarizes underlying concepts, history, impacts, and status of "transit benefits," a tax incentive strategy for involving employers in efforts to reduce traffic congestion, greenhouse gas emissions, and energy use, by promoting public transit use. Transit benefits - tax-free employer-provided benefits for public transport-is the government tax policy in which transit fares are a tax-free employer- 
and/or employee-paid benefit, delivered using an array of programs and services provided to employers. Transit benefits are formally authorized under Section 132(f) of the United States (U.S.) Internal Revenue Code.

\section{Economics and Free Parking}

The first employer-based transit programs arose in the 1970s as transit agencies began using monthly passes and sought primarily to have employers be supplemental pass sales outlets. For example, after Massachusetts Bay Transportation Authority monthly passes were introduced, their popularity and the limited number of public sales outlets led many employers to become "private" sales outlets for their employees. As passes and employer-based sales spread to other cities, employers also were encouraged to pay for passes in whole or part. Used informally for years before, employer fare discount plans - transit benefits - were first authorized by the Tax Reduction Act of 1984, with use limited to employer subsidy of no more than $\$ 15$ per month. Their use became popular in the late 1980 s, and through the 1990s appeal expanded rapidly as the tax-free maximum rose and an employee-paid option and new administrative services were added.

Due to the tax savings and employee appeal, transit benefits are now used to varying degrees in every U.S. city. They are a standard employee benefit in New York, Chicago, Boston, San Francisco, Seattle and elsewhere. Reviewing pertinent economic theory and transit's overall market context helps understand how this was achieved, and its importance.

National Personal Transportation Survey data show that for all purposes, free parking is available for 99 percent of daily trips (Hu and Young 1998). The impact of free or partly-subsidized work-based parking (Shoup and Pickrell 1980; Wilson and Shoup 1992; Wilson and Shoup 1997) is one reason transit benefit tax policies were first established and later expanded by the government, and embraced by employers. The public policy behind transit benefits can be understood using the economics principle "theory of the second best," formalized by economists Richard Lipsey and Kelvin Lancaster in 1956. Free or subsidized parking is a market "distortion" yielding social "externality" costs borne by third parties. These costs include pollution, congestion, inefficient energy use, and many other direct and indirect impacts of auto-focused policies. Density, largely reflecting the amount of land devoted to parking, often defines the level of transit service that is viable. Hav- 
ing less transit service provided than otherwise might be can also be considered an economic externality.

It is hard to understate the role of workplace parking policies in urban transportation. Free parking is a potent market distortion with profound effects on transit demand, auto ownership, land use patterns, and home ownership decisions, such as commuting distance or the choice between an apartment or single family residence. In short, it promotes low-density lifestyles that can even be linked (Owen 2009) to decisions about family size. Economists say that if market distortions cannot be corrected directly, as a "first best" solution, introducing a "second best" solution is appropriate. Transit subsidies in general and specifically transitpromoting tax incentives focused on the workplace are thus justified as "corrections."

Free parking is difficult to address and not a solely American practice. In Canada, England, and Australia where it is technically not authorized as a tax-free benefit, for example, it is still widely provided by employers. For tax purposes, owing in part to many direct and indirect ways parking subsidies are provided in different settings, it is impossible to consistently identify parking costs or benefits, which makes the provisions largely ineffective. For example, it is hard to place a value on parking spaces adjacent to a building, especially if the number of spaces or building setback is mandated by municipal code, or when customers and employees share parking. For tax purposes, free and discounted employee parking is a ubiquitous but elusive practice, especially in suburban settings. Even when employers do not provide parking, the many other external/social costs of auto use justify favorable tax policies for transit users, and given the determinant role of commuting decisions, a focus on employers is most effective.

Parking subsidy clearly promotes auto use, but existence of auto subsidies (even just on-site parking spaces) also makes transit benefits attractive to employers. For employee benefits, employers are very sensitive to equity and strongly favor benefits that can be used by all employees. With many employees already receiving free or discounted parking, many employers embraced transit benefit plans as they became administratively practical, partly due to pressure from transit-using employees wanting commuting benefits "equalized." The 30 years of U.S. experience with transit benefits shows that transit benefit plans reflecting employer sensitivities-which foremost means they reflect employer concerns for simplicity and equity - can be readily and successfully marketed. This also means that the theory of the second best can work. 
Transit does not serve many employment sites, and in general far fewer employees are offered tax-free transit than parking even where transit service exists. Yet in some cities large shares of transit users get transit benefits. For example, a 2006 study (Bay Area Rapid Transit District 2006) reported that 43 percent of San Francisco's Bay Area Rapid Transit riders work for employers offering a transit benefit plan, an increase from 39 percent in 2003. The 2006 measure is 63 percent when the data are adjusted to reflect only employed peak-period commuters. A series of innovations caused this important change in the U.S. transit industry.

\section{Experience to Date}

U.S. transit benefits are provided in two alternate ways, and a third combines the two. The initial application was "employer subsidy" for transit, with the practice directly analogous to employer-paid (or provided) parking, where the expense is borne by the employer.

The more recent and popular application has employees paying transit fares using before-tax salary; deductions are made from gross salary before income or payroll taxes are applied. This is a "pre-tax benefit" in the U.S. and "salary sacrifice" elsewhere in the world.

The third or combination alternative is "fare sharing." Here, the employer pays part of the benefit as a tax-free subsidy and the employee pays the remainder with pre-tax salary. In practice, beyond the basic options, employers adopt numerous variations to make their plan consistent with the employer's overall benefits and "corporate culture." For example, employers might subsidize half of employee fares or a flat amount such as $\$ 30$ per month, or require participation for a certain number of months. U.S. law allows many variations, which is surely an important element in the acceptance the programs have had.

Table 1 summarizes key junctures in the evolution of transit benefits. It was formally established in U.S. tax code in 1984, partly to clarify the status of informal practices known as "employer pass plans" existing in some cities. Some cities had large pass plans, and it is notable that these cities had basically one transit operator, in contrast to other cities with multiple providers. In pass plans, employers buy monthly passes (the programs being limited to passes is important) and sell them to employees, sometimes at a discount, with the benefit tax-free. The process can be complex; employers need to order the correct number of passes (often more than one type), receive and store them, distribute them monthly, receive 
payments/co-payments from employees, return unused passes, pay the transit operator (consignment sales were most common, with monthly reconciliation), etc. Employees often change their requirement, e.g., for a vacation or month with business trips or holidays. These administrative requirements gave pass plans limited use, except in a few cities such as Seattle and Boston, where they did become popular with larger employers. Cities with complex transit networks (those with multiple modes, operators, and zonal fares, as in New York and Chicago) did not have pass programs, mostly due to the even greater burden an employer would have. Employers with staff in multiple cities often could not provide comparable benefits to all employees, so these employers most often did not participate. Overall, few employers participated. Employer pass plans also are costly for transit agencies to operate.

Table 1. Highlights of U.S. History with Transit Benefits

\begin{tabular}{ll}
\hline 1970 s & Employer pass programs emerge \\
1984 & Legislation “codifies" use of transit benefits, allowing $\$ 15$ per month \\
& maximum benefit ("cap"); limited to employer subsidy \\
1987 & First transit voucher plan implemented in New York \\
1990 & First Eco-Pass plan implemented in Boulder and Denver \\
1990 s & Self-supporting national transit benefit services emerge \\
1991 & Inflation adjustment raises transit benefit cap to $\$ 21$ \\
1992 & New legislation raises cap to $\$ 60$ per month \\
1995 & Inflation adjustment raises cap to $\$ 65$ \\
1998 & Employee-paid pre-tax payroll deduction feature added \\
2000 & Executive Order mandates transit benefits for Federal employees \\
2002 & Monthly maximum benefit raises cap to $\$ 100$ \\
2005 & Inflation adjustment raises cap to $\$ 105$ \\
2007 & Inflation adjustment raises cap to $\$ 110$ \\
2008 & Inflation adjustment raises cap to $\$ 115$ \\
2008 & City of San Francisco adopts transit benefit ordinance \\
2009 & January: Inflation adjustment raises cap to $\$ 120$ \\
2009 & February: New legislation (2009 legislation limits the increase for two years) \\
2009 & raises cap to $\$ 230$, matching the cap for tax-free parking. \\
& Transit benefit ordinances adopted in California by City of Richmond, San \\
& Francisco Airport Authority, City of Berkeley \\
\hline &
\end{tabular}


Despite limited use, the untapped promise in this area and market research findings showing over 80 percent of drivers entering lower Manhattan received some type of employer auto subsidy (most often free or subsidized parking) led transit agencies in New York to seek clarification of the practice in the tax code. As a result, the 1984 legislation defined the transit benefit as a "deminimus benefit" and established its maximum value at $\$ 15$ per month. Focused program development efforts began in New York City in 1984.

Regulations following the 1984 legislation allowed the benefit to be provided as passes, tickets, tokens, or vouchers. Allowing vouchers (they had not yet been used) reflected a desire to devise transit benefit plans in cities with more than one transit provider, e.g., New York, San Francisco, Philadelphia, and Chicago. Vouchers were seen as a way for employer participation to be widespread and even simple for most employers. Focus groups found administrative simplicity vital to employer consideration of any fringe benefit. This supported the decision to develop vouchers, as an employer pass plan in New York could require employers to handle dozens of fare instruments for the many rail, bus, and ferry services and different pass types and fare zones. In contrast, vouchers are script (in most cities, specialized bank checks) that employers simply buy and give to employees, who redeem them where all participating operators' passes or tickets are sold. That they do not expire from month-to-month also simplified administration. Figure 1 illustrates a transit voucher currently in use.

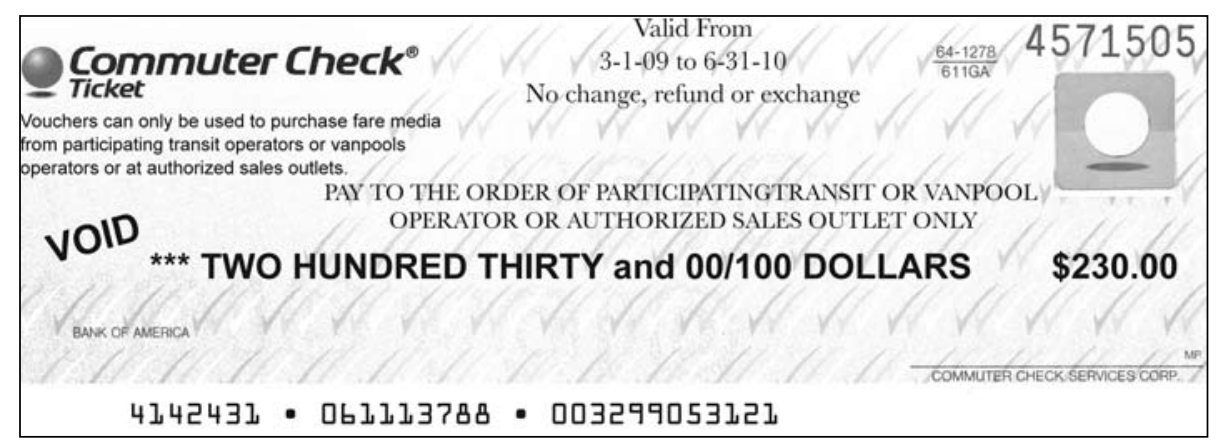

Figure 1. Transit Voucher

Focused purely on transit subsidy and piloted by a multi-agency effort of New York City transit operators as a Federal Transit Administration demonstration project, the first voucher plan began in 1987. The administrative advantages and simplicity of vouchers enabled the plan to quickly find success. Compared to employer pass 
plans that sought primarily to have employers be pass sales outlets, private sales outlets were not needed in New York, and the voucher plan sought what employers could uniquely provide: subsidy and tax benefits. It became clear that asking employers to be sales outlets and provide subsidies meant that, in most cases, they simply did not participate. Many transit pass plans also had minimum order quantities, which meant, by definition, that small employers could not participate. In contrast, according to the U.S. Census Bureau's Statistics on U.S. Businesses, 71 percent of U.S. employers have fewer than 20 employees.

While some cities developed local programs, scale economies and employer willingness to pay nominal fees led nationally-focused transit voucher services to emerge. Within a few years, "TransitChek" and "Commuter Check" vouchers served over a dozen cities. Transit agencies gained rides and revenue, and privately-operated programs meant transit agencies had little if any expense. Many provided marketing assistance, e.g., posters in buses and trains. The cost to transit agencies of receiving and processing vouchers was generally minimal, usually negligible. As the vouchers were bank checks, they most often were received and deposited by private sales outlets (e.g., groceries), with transit agencies not even receiving them.

Vouchers had new features reflecting employer needs (Oram 1990). As a "least common denominator" instrument, they were something all employees could use. Employers usually did not have to worry about which one was for which employee; they were essentially interchangeable and did not expire for over a year. The plans were not limited to monthly pass users and avoided employee co-payment, a serious limitation of most employer pass plans. With vouchers redeemable for any fare type, less-than-regular and even infrequent riders participate, which is critical for many reasons. Keenly sensitive to equity, most employers simply will not adopt programs if only some transit-using employees can participate.

Even if an employer adopts a program limited to passes, it yields far less new ridership than a broader plan. Research found induced transit trips resulting from voucher plans most often reflecting non-users becoming occasional users and occasional users riding more (Metropolitan Transportation Commission 1995). Instances of non-users converting to regular users were rare. Consistent with this, a "transit rider life cycle" was observed (Perk et al. 2008); on-board surveys found that most riders began using transit for occasional work trips, and if they continued riding — many did not — they increased their use and sometimes added 
off-peak trips. The studies also suggested transit benefits would diminish turnover (rider attrition), which was found to be significant.

Transit commuters are typically thought to ride every day, but U.S. and Canadian studies found less-than-regular riders comprising a large and often majority share of transit commuters. A paper (Oram and Stark 1997) published by the U.S. Transportation Research Board reported these "surprising" findings and suggested that transit marketing, advertising, pricing levels, and fare structure needed rethinking. A national study (Federal Highway Administration 1997) stated, "Those who say they use transit to get around constitute about 27 percent of transit riders, with usual auto users who use transit only on an occasional basis constituting about 62 percent."

To include these users, transit benefit plans cannot be limited to passes. For example, if a pass costs $\$ 50$ and an employer provides a $\$ 20$ subsidy, employees do not save anything until $\$ 30$ in rides is taken; hence, most employees are left out. Additionally, someone who already rides that much is unlikely or even unable to ride much more. This suggests, counter-intuitively and unlike most employer pass plans, that the most important target for a transit benefit plan is the less-thanregular and infrequent rider market segments. The role of infrequent riders means a large share of employees can participate in programs not limited to passes. Rather than serve relatively few and thus have less appeal to employers, vouchers can serve most employees; over a period of a year, virtually all employees may be able to use a $\$ 20$ voucher, for example. This is vital, as most employers won't adopt benefits serving few employees. Thus, serving infrequent riders is critical and arguably the core reason that transit benefits gained wider use. Again counter-intuitive, being able to serve the large number of irregular or even infrequent users "drives" the success of a transit benefit initiative.

The market data above on the role of infrequent riders, supported by transit benefit program experience, suggest that if infrequent use is not a primary focus, employee participation will be less than half of what it otherwise would be. And assuming at least five times the number of employers join simpler and broader programs (based on experience, this is a conservative estimate), one can conclude that a plan that accommodates infrequent users as well as pass users would have at least 10 times the participation of a plan limited to regular (pass) users. Furthermore, as regular riders are far less able to expand transit use, the impact of a broader program will be far more than a factor of 10 . 
Being simpler, more equitable and applying to the "first dollars" of fares, vouchers profoundly increased interest in and impacts of employer transit programs. It was a breakthrough that re-wrote the book. Voucher plans enrolled thousands of employers in large cities and created a new ridership and revenue tool for mediumsized and smaller cities. Vouchers changed a peripheral idea to an important part of transit marketing and revenue generation strategies, and employer benefit packages. Having the private sector operate the programs and provide substantial marketing support also was critical and perhaps unique.

Compared to the pass plans that generally appealed to relatively few and mostly larger employers, vouchers appealed to far more and were notably effective in drawing thousands of small employers, where there was previously no participation. As employers need to stay competitive with their peers regarding benefits and are especially interested in low-cost benefits, added participation and validation of the benefit by smaller and medium-sized employers prompted larger ones to also enroll-a virtuous cycle began. Like infrequent riders, discovering the role of smaller employers was another key to the expansion of U.S. transit benefit programs.

Having found market appeal, transit benefit advocates succeeded over the years in expanding the enabling legislation. In 1991, the \$15 limit became \$21 as an inflation adjustment was adopted due to the demonstrated interest and resulting political pressure. Legislative changes brought further increases and massive broadening of the provisions via the 1998 introduction of the employee-paid pretax option. One of the changes established a cap on parking benefits, which was previously tax-free at any level. An Executive Order signed by President Clinton established transit benefits for Federal government employees. A series of inflation adjustments brought the cap to $\$ 115$ in January 2008 and $\$ 120$ in January 2009, and as part of the 2009 Economic Stimulus Bill, transit and parking benefits were equalized at $\$ 230$ (at least until 2011). It took 25 years, from 2004 until 2009, for the authorized transit benefit cap to reach parity with parking.

Table 1 noted EcoPass plans appearing in 1990. EcoPass began in Boulder and Denver as a way to provide discounted fares, primarily for university students (in some cities, it is called UniPass) but later for employers as well. They are almost always limited to settings with one transit operator. EcoPass entails the university or employer purchasing, under contract with the transit agency, annual transit passes for all of its students or employees, at a discounted price. With free access, experience has shown (Brown et al. 2003) that EcoPass generates considerable 
new ridership, regardless of a rider's trip frequency. It does not build revenue, at least initially, and can lead to added service requirements, but is very popular. The EcoPass concept appeals partly because it entails no ongoing administration. The initial intent was that the employer would subsidize the annual contract amount, which would be a tax-free subsidy, but in many cases employers devised an employee monthly co-payment so that the employer removed or diminished its cost. The co-payment made EcoPass somewhat like the traditional employer pass plan, though it was less than the normal pass cost. As the law changed, some employers allowed the employee payment as a pre-tax deduction. EcoPass is primarily a marketing and fare collection plan and secondly a transit benefit option and can have serious long-term net revenue implications (e.g., revenue growth less added service requirements, and resistance to higher fares by employers). It was important to drawing employers into transit programs, but except at universities, is not likely to expand considerably.

\section{Newer Services}

With the market established, other innovations were equally important in expanding transit benefit use and will be increasingly important going forward. As internet commerce emerged, new transit benefit programs further tailored the transit benefit to employer needs. Vouchers did not appeal to many larger employers (although many do use them, e.g., the U.S. Government) and also were not well suited to needs of employers with offices in different cities. For these, "on-line/at-home" programs were devised. Many larger and multi-site employers disliked having to purchase, store, and distribute vouchers (which varied by city) and wanted streamlined procedures to match employee fares with their payroll systems. On-line programs, using websites taylored to reflect particular provisions of the employer, enabled employees to specify their ticket/pass/voucher need for the upcoming month or quarter, or set a standing order. Program administrators, again self-supporting private businesses, provided the employer with a "payroll file" tailored to the employer's needs. When the employer made the payroll deductions and paid the administrator for the fare media and service fee, the administrator mailed the passes or vouchers to employee homes. Some employers pre-pay an estimated amount to avoid delays.

The convenience of "at-home" programs gave transit benefits further market penetration, especially with larger employers. That the cost of this enhanced service exceeded voucher fees was generally a subordinate consideration. Some employ- 
ers, however, opted for a voucher-only at-home service; as vouchers did not need to be mailed every month, this was very economical. Based on a cost-per-fulfillment rather than percentage of face value as vouchers involve, at-home programs gained a cost advantage as the monthly cap rose. A "direct load" to smart cards is another and increasingly important feature.

Further growth resulted by integrating transit benefits with "third-party administrator" (TPA) services. TPA companies administer payroll, health, retirement, and similar plans. Most large employers and many medium-sized and smaller ones use TPAs. By drawing these "major players" into the transit benefit field, one can say the transit benefit "came of age."

Smart cards presented challenges but ultimately resulted in another opportunity to expand transit benefits. The Washington, D.C. transit system led the way in this area. Essentially, transit benefit value must be transmitted electronically to the smart card administrator and each employee's card. The on-line/at-home plans did this, but not all employers found this model attractive relative to vouchers. In general, integrating transit benefits with smart cards entailed significant complexities, as (like the early pass plans) most employers do not want to be involved in details of employee fare payments. One informed observer noted that smart cards and transit benefits were on a collision course. To avoid this, smart cards can be integrated with transit benefits using a "virtual voucher" or "e-voucher" to marry the appeal and efficiency of vouchers with the conveniences of smart cards and the internet.

An e-voucher entails the employee receiving a unique "voucher" number for one-time use on a specialized website, where the employee applies the value for individual rides, a pass, etc. This meant the employer's role could be even simpler than with paper vouchers, as virtual vouchers are electronic and do not necessarily require anything to be distributed. This is particularly attractive to employers who do not use TPAs or do not want or cannot have an on-line ordering platform integrated with their payroll system. The e-voucher can have lower costs for employers and transit agencies.

Being electronic, e-vouchers are not physically redeemed. The value is "contained" in the number and not on a piece of paper where it may be printed. E-vouchers can even be distributed simply as e-mail messages. Another important feature of an e-voucher is that customer service is handled either by the transit benefit service provider or smart card administrator, with employers essentially uninvolved. As smart cards are used in more cities, e-vouchers may become a core way to 
administer transit benefits, replacing paper vouchers, at-home delivery, and other means. An e-voucher can avoid the transit benefit/smart card collision.

Debit cards are another way to deliver transit benefits in cities where fare vending machines, ticket-by-mail plans and smart cards are used. The initial personalized debit cards met market resistance. Some vendors, often TPAs using debit cards for other benefits, felt debit cards would be the best way to offer transit benefits, but their limited initial "pick up" affirms the key employer concerns for simplicity and universality. Unlike vouchers, personalized debit cards associate a specific person and card number with the requested value and "re-loads." The debit cards also required personal user information, which raised privacy and security issues. They also entailed more customer service than vouchers.

Initial efforts with personalized debit cards proved that they would not be a sole solution for employers or employees, and they did not gain significant market share. Furthering this were Internal Revenue Service regulations issued in 2006 on the use of transit benefit debit cards. The regulations phased-in restrictions to limit and ultimately (in 2011) preclude their use in situations where employees might receive cash from the card, e.g., retail sales outlets. This made debit cards less attractive than vouchers, the majority of which are redeemed at retail outlets, or an at-home service. Customer service issues also arose, many related to the non-transferable nature of personalized cards, which is not a factor for vouchers. Many of the TPA vendors withdrew their cards, but others with expertise in the transit industry made their programs fully compliant and efficient for employers and users.

To avoid many of the personalized card issues, a streamlined non-personalized debit card ("stored value card") was devised; this is more popular but still has re-loading, customer service, and other complexities. When used at transit fare vending machines, debit cards also impose 2-3 percent transaction fees on transit agencies and, as they are discarded after use, they create trash and environmental concerns. It remains unclear how important debit cards, in any form, will be to the future of transit benefits. They are less attractive when most transit fares are bought at retail outlets, but are needed in some cities and will likely be more attractive as automated fare collection serves more cities and users.

Transit fare collection procedures vary greatly from city to city. This adds to the varying preferences that employers have and means that a single solution for administering transit benefits likely does not exist. What is efficient or attractive in one city is often less attractive or unworkable in another. What one city sees as a cost, such as debit card transaction fees that can be avoided with a retail sales net- 
work, may be accepted in another city as just a cost of automated fare collection and offset by those benefits. Going forward, debit cards with embedded chips, cell phone, and other emerging payment technologies may be important in fare collection, which means they also would gain use in transit benefit plans. As with the current options, each will have pros and cons. Like employer-supported parking, transit benefits likely will always be provided in numerous ways. Transit benefits will hopefully become just as integrated as parking is as an employee benefit.

Table 2 presents the sequence in which the transit benefit administrative options emerged. Most notable is their evolution regarding the employer's key concern: simplicity and administrative ease. Increased efficiency and thus participation resulted when vouchers became the primary mechanism. EcoPass provided an annual option. Further efficiency resulted as on-line programs emerged to meet needs of larger and multi-site employers, and bring in TPAs. Debit cards are needed and work well in some cities. Serving smart cards will yield further efficiency by allowing the "tangible" elements and activities to disappear.

\section{Table 2. Evolution of Transit Benefit Administration Options}

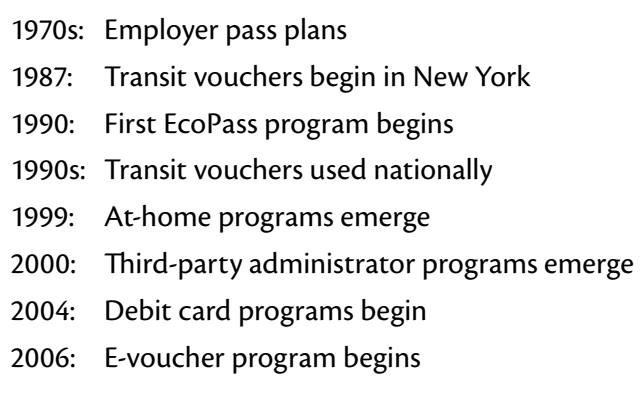

Tables 3, 4 and 5 offer opinions on the relative appeal, market impacts, and promise of the options now used. While vouchers gave transit benefits broad appeal, integrating transit benefits with the constantly-evolving technology of fares and benefits quickly became important and will be increasingly vital as transit benefits reach ever-more employees. In sum, a self-supporting industry with robust services emerged to meet diverse employer needs and provide tax savings and transit incentives to reduce auto use where such efforts are most effective, at the workplace. 


\title{
Table 3. Relative Appeal of Transit Benefit Administration Options
}

\author{
Employer Pass Plans: \\ Larger employers, generally located in one city \\ Voucher Plans: \\ Initially smaller employers, subsequently larger \\ EcoPass Plans: \\ Generally universities and larger employers \\ At-Home Plans: \\ Generally larger employers, often multi-city \\ Third-Party Administrator Plans: \\ Medium to larger employers, all cities \\ Debit Card Plans: \\ Large employers, often multi-city \\ E-Voucher Plans: \\ Employers in cities with smart card fare collection
}

\section{Table 4. Relative Impact of Transit Benefit Administration Options}

\begin{tabular}{|c|c|}
\hline Employer Pass Plans: & $\begin{array}{l}\text { Ground-breaking option but limited appeal and } \\
\text { only in some cities }\end{array}$ \\
\hline Voucher Plans: & Rapid growth into new markets, validated concepts \\
\hline EcoPass Plans: & Substantial impact on ridership in a few cities \\
\hline At-Home Plans: & Substantial appeal in most major markets \\
\hline Third-Party Administrator Plans: & Substantial appeal in most major markets \\
\hline Debit Card Plans: & $\begin{array}{l}\text { Appeal limited to cities where credit/debit cards } \\
\text { are accepted }\end{array}$ \\
\hline E-Voucher Plans: & $\begin{array}{l}\text { To be determined as smart card fare collection } \\
\text { expands }\end{array}$ \\
\hline
\end{tabular}

Table 5. Future of Transit Benefit Administration Options

$\begin{array}{ll}\text { Employer Pass Plans: } & \text { Use has declined and will continue to } \\ \text { Voucher Plans: } & \text { Unclear; large markets still not penetrated but } \\ & \text { conversion to new options occurring, esp. in automatic } \\ & \text { fare collection cities } \\ \text { EcoPass Plans: } & \text { Unlikely to expand except in university or similar settings } \\ \text { At-Home Plans: } & \text { Substantial growth likely } \\ \text { Third-Party Administrator Plans: } & \begin{array}{l}\text { Substantial growth likely } \\ \text { Debit Card Plans: }\end{array} \\ & \text { Substantial growth likely as automatic fare collection } \\ \text { E-Voucher Plans: } & \text { expands } \\ & \text { Likely very important as smart card fare collection } \\ & \text { advances }\end{array}$




\section{Impacts of Transit Benefits}

Conceptually, impacts of transit tax incentives can be projected using standard measures of fare change sensitivity, or elasticities, observed from decades of fare changes. Summarizing experience with price changes, Litman (2009) notes work trips are especially insensitive to fare changes, reporting elasticities ranging from -0.1 to -0.19 . Assuming an average of -0.15 , a 10 percent fare change would lead to a 1.5 percent change in ridership. (The minus sign indicates the inverse relationship between fares and usage.) The -0.15 figure, however, is an average; different measures for bus vs. rail, small vs. medium vs. large cities, urban vs. suburban settings, fare types, rider categories, and other factors have been determined. In considering transit benefit impacts, it is important to consider that a -0.15 average figure also does not reflect significant differences in sensitivity shown by regular vs. infrequent riders, e.g., a rider changing all trips to transit or just a few (Lewis and Williams 1999; Tromer et al. 1995; Oram 1988, 1994). Also notable is that fare change sensitivity is generally inverse to city size, suggesting transit benefits can have more impact where auto use is greater. Still, the -0.15 work trip elasticity can be used when considering changes over broad areas.

Using the -0.15 factor, Table 6 shows the transit ridership changes that transit benefits would be projected to yield. The pre-tax benefit would yield a savings of about 30-40 percent for most riders, resulting from savings in Federal income and payroll taxes and state taxes. Using the -0.15 elasticity measure, a 40 percent savings would be expected to yield a 6 percent increase in transit trips $\left(-0.4^{*}-0.15=\right.$ 0.06). The 30 percent savings would yield 4.5 percent more riding. A subsidy program, where an employer reduces its employees' fares by 50 percent for example, would be expected to build ridership by 7.5 percent $\left(-0.5^{*}-0.15\right)$. Full subsidy of employee fares, i.e., a 100 percent reduction, could be expected to yield 15 percent ridership growth $(-1.00 *-0.15)$.

\section{Table 6. Elasticity-Based Projections of Transit Benefit Ridership Changes}

Pre-Tax Benefit Tax Savings

- $40 \%$ work trip fare reduction

- $30 \%$ work trip fare reduction

Fare Subsidy Savings

- $50 \%$ work trip fare reduction

- $100 \%$ work trip fare reduction
Theoretical Impact

$-40 \% *-0.15=+.060=6 \%$

$-30 \% *-0.15=+.045=4.5 \%$

Theoretical Impact

$-50 \% *-0.15=+.075=7.5 \%$

$-100 \% *-0.15=+0.150=15 \%$ 
The actual impacts of transit benefits are much greater than these elasticity projections suggest. Many studies have been done, in many different settings (major/ older cities in the eastern U.S., newer western cities, urban and suburban settings, etc.). Subsidy as well as pre-tax plans have been evaluated. Sponsored by the National Academy of Sciences, 22 of these local studies were reviewed and summarized by national studies done in 2003 (Transportation Research Board 2003) and 2005 (Transportation Research Board 2005).

\section{Subsidy Impacts}

A 1994 study of the San Francisco Bay Area Commuter Check voucher program (Metropolitan Transportation Commission 1995) was done before the pre-tax option existed and thus considered only subsidy. Its general finding was that transit use rose an average of 34 percent as a result of partial fare discounts, which were normally just $\$ 20$ or $\$ 30$ per month and a maximum of $\$ 60$. These programs clearly had more impact than elasticities would suggest. It also found differences in the level of new riding at San Francisco employers compared to those elsewhere in the region. The average growth in ridership at San Francisco employers was 25 percent, but it was 43 percent at suburban employers. Most of the new use came from non-users riding some and infrequent riders riding a bit more, and not as "full converts" from auto to transit use. While regular riders were generally the "activists" that pressed their company to adopt the plan, the increased use primarily came from other employees.

The very strong "infrequent use" impacts can be considered as follows. As most employers provided fractional subsidies using vouchers requiring no employee co-payment, transit use for a certain number of rides was free. That is, even though a $\$ 20$ subsidy might be just a 33 percent discount on a regular rider's $\$ 60$ pass, its effect on infrequent usage would be stronger; in fact, it means free fares up to a certain level. This simply indicates the very positive impacts resulting when a transit benefit plan is designed with a focus on building infrequent ridership, and expressly avoiding employee co-payment of any sort. As discussed above, this was the major change that vouchers achieved compared to pass plans.

\section{Pre-Tax Impacts}

The newer and now more popular use of transit benefits is the pre-tax plan. This is easier to analyze, as all employees, regardless of frequency, enjoy the 30-40 percent 
tax savings. The 40 percent savings and -0.15 elasticity factor suggest ridership under these plans should grow about 6 percent $(-0.4 *-0.15)$. However, the 2005 national study (Transportation Research Board 2005) reported ridership gains of 3 percent to 155 percent and an average gain of 39 percent. While this figure is similar to the findings of the 1994 San Francisco study's findings, which generally reflected $\$ 20$ and $\$ 30$ subsidies, the 2005 pre-tax results reflected the higher benefit levels available at that time. Other things equal, impacts of employer subsidies are notably higher than for pre-tax.

\section{Interpretation}

Why do transit benefits-either type or the combination-have so much more impact on ridership than elasticity factors project? One suggestion reflects the larger increases seen at employers outside San Francisco vs. those in San Francisco. The greater "induced use" in suburban areas is consistent with elasticity data showing larger response to fare changes in smaller cities and the greater incidence of free parking "distortions" in suburban areas. Parking is virtually always provided free in non-urban settings in the U.S. If the existing auto subsidy was offset by the transit benefit plan, it suggests the theory of the second best as an explanation. As parking subsidies are far less common within San Francisco, there was less distortion to offset, meaning less of an immediate increase in use.

Perhaps the results are just different from the -0.15 elasticity average. As noted above, infrequent riders have very different elasticities than regular riders. And there are no elasticity data predicting riding changes specifically when free parking is available. Both of these explanations further suggest the importance of transit benefits.

Relative to general fare-level changes, a primary focus on existing transit riders and the lower results that elasticity projections suggest, it appears that the workplace, where all commuters can be directly marketed, is simply the best place to focus fare incentives and promote transit use. Employers have special abilities to encourage or discourage transit use; the tax savings provided by transit benefits thus elicits employer support in other tangible and intangible ways. Many employers, for example, direct staff time to promoting transit use or provide other types of transit marketing support, realizing it is a good employee benefit with valuable results for the employer (recruiting and retaining staff, productivity, parking savings, etc.), in addition to tax savings. Transit use becomes part of corporate culture, a positive 
part. Transit benefits help companies be seen as "sustainable" and a good place to work; the "Best Workplaces for Commuters" program was developed by the U.S. Environmental Protection Agency to provide this recognition.

By delivering employer support, transit benefits improve transit's overall market context, diminishing the typical bias favoring auto use. The theory of the second best works! As commuting often determines car ownership and home location decisions, one can argue that workplace marketing of transit, and thus the transit benefit, is vital in re-framing transit's market position. Even from a short-term focus on transit ridership and revenue maximization, the argument for increased attention to transit benefits is compelling.

The best evidence of the broad support transit benefits now enjoy and the continued promise for substantial impact is the adoption of municipal ordinances mandating the use of transit benefits by employers with 20 or more employees in 2008 and 2009 by four municipal governments in the San Francisco Bay Area: City and County of San Francisco, City of Richmond, City of Berkeley, and the San Francisco Airport Authority. The latter affects numerous airlines, food service, and other large airport employers and includes a \$200-per-day fine for non-compliance. It is notable that all of the local Chambers of Commerce supported their respective ordinances, as did other business groups. That the transit benefit provides tax savings to employers and employees, and requires minimal administration, likely offsets the natural opposition of business groups to new regulations.

This new regulatory dimension will surely yield massive expansion of transit benefit use. If replicated widely, and especially where free parking is common, it could fundamentally change transit's market position.

Shoup (1992) and other transportation professionals support the "Parking Cash Out" strategy that allows employees to elect more salary in lieu of a parking subsidy. While technically sound, this idea has not gained broad use, partly due to added taxes employers and employees pay as a result of salary increases. Some employers administer Cash Out on a daily basis, but it generally does not reflect the infrequent use factor-that many employees prefer using transit some days and driving on others and are thus reluctant to relinquish parking spaces. Cash Out would be a "first-best" solution to the auto subsidy problem, but its limited appeal suggests the "second best" transit benefit solution is a better one overall. 


\section{What's Next?}

Transit benefit plans are popular with employers, employees, and government policy makers, and have impressive results when designed well. Researchers and most professionals in the transportation demand management (TDM) field believe financial incentives are vital for employer-based traffic reduction programs to have more than nominal impact. Reflecting the strong reluctance by employers to charge for parking and the excellent match with "corporate culture" that transit benefits can provide, many believe transit benefits are the most potent TDM measure that can have wide appeal. It's a second best action, but appears to be the one that can induce the most overall change. Transit benefits also can be a catalyst for employer use of other TDM actions (such as guaranteed ride home programs or flexible work hours), which can further and often dramatically magnify the overall impact of transit benefits.

Whether one feels the lost tax revenue implicit in transit benefits is desirable likely reflects one's views about auto subsidies and transit overall. Yet it is not arguable that, intentionally or not, public policy delivers auto-related subsidies, which means transit also deserves subsidy as most, if not all, developed countries do. Thus, the question becomes whether employer-based tax (user) incentives are a cost-effective way to increase transit ridership and supplement general (capital or operating) subsidies for transit systems. Broad evidence suggests they are. Some economists believe "user side" subsidies are always preferable to "supplier side" subsidies.

At every level, automobile subsidies are ingrained in American transportation. Just at the worksite, free parking and auto subsidies are provided in myriad ways: company-provided cars, on-site parking in lots and structures, parking provided at third-party locations, company-paid parking subsidies, employee-paid pre-tax parking, etc. As reviewed here, over the past 30 years, the transit benefit evolved to compete quite well, with a robust set of products: pass plans, vouchers, EcoPass, on-line programs, smart card programs, e-vouchers, debit cards, stored value cards, etc. By tailoring programs to the varying needs of employers, transit benefits have offset at least some of the effects of free parking. In sum, it appears that employer-based transit incentives are one of the best ways to promote transit use, due to their demonstrated broad appeal, their ability to directly offset the auto subsidies in place at most worksites, and the long-term benefits that offsetting such subsidies can deliver. 
The new "transit benefit industry" is also a notable and profoundly successful example of public-private cooperation, delivering new transit marketing resources from employers and transit benefit administrators. It is estimated that three million U.S. transit users now participate in transit benefit plans nationwide. This is an impressive achievement, but the opportunity for further market penetration remains enormous. Free parking is still the rule, and transit benefits are not offered at most employers. That the current $\$ 230$ transit benefit cap equals the parking cap, or that an array of transit benefit service options now exists, does not mean there has been substantial impact on the basic land use, transportation investment, or other dimensions of our automobile subsidy culture. Still, huge advances were made and the first 30 years are just that ... the first 30 years.

\section{References}

Bay Area Rapid Transit District 2006 Customer Satisfaction Survey; further interpretation provided by Robert Lockhart, BART Market Research Manager.

Brown, J., et al. 2003. Fare free public transit at universities: An evaluation. Journal of Planning Education and Research 23(1), Fall.

Federal Highway Administration. 1997. Transportation users' views of quality. U.S. Department of Transportation.

Hu, P., and J. Young. 1998. Summary of travel trends. 1990 Nationwide Personal Transportation Survey. Federal Highway Administration.

Lewis, D., and F. Williams. 1999. Policies and Planning as Public Choice: Mass Transit in the United States. Aldershot/Ashgate.

Litman, T. 2009. Transportation elasticities: How prices and other factors affect travel behavior. Victoria Transport Policy Institute.

Metropolitan Transportation Commission. 1995. Impact of Bay Area Commuter Check Program: Results of 1994 employee survey.

Oram, R. 1990. Transit vouchers and employer fare subsidies. Urban Mass Transportation Administration, U.S. Department of Transportation.

Oram, R., and S. Stark. 1997. Surprise, surprise: Infrequent riders are a key to new transit ridership and revenue. Transportation Research Board. 
Oram, R. 1988. Deep discount fares: Building transit productivity with innovative pricing. Urban Mass Transportation Administration, U.S. Department of Transportation

Oram, R. 1994. Implementation experience with deep discount fares. Research and Special Programs Administration, U.S. Department of Transportation.

Owen, D. 2009. Green Metropolis: What the City Can Teach the Country about True Sustainability. Riverhead Books.

Perk, V., J. Flynn, and J. Volinski. 2008. Transit ridership, reliability and retention. National Center for Transit Research, University of South Florida.

Shoup, D., and D. Pickrell. 1980. Free parking as a transportation problem. Urban Mass Transportation Administration, U.S. Department of Transportation.

Shoup, D. 1992. Cashing out employer-paid parking. Federal Transit Administration, U.S. Department of Transportation.

Transportation Research Board. 2003. Strategies for increasing the effectiveness of commuter benefits programs. Transit Cooperative Research Program Report 87, National Academy of Sciences.

Transportation Research Board. 2005. Analyzing the effectiveness of commuter benefits programs. Transit Cooperative Research Program Report 107, National Academy of Sciences.

Tromer, S., M. Jewell, R. Peskin and J. Schwenk. 1995. Evaluation of deep discount fare strategies. Research and Special Programs Administration, U.S. Department of Transportation.

Wilson, R., and D. Shoup. 1992. Employer paid parking. Transportation Quarterly 46(2).

Wilson, R., and D. Shoup. 1997. The high cost of free parking. Access 10, Spring.

\section{Acknowledgments and Authors' Note}

This paper, offering observations, opinions, and interpretations of practitioners in the transit benefit field, is less academic than most appearing in the Journal of Public Transportation. We appreciate the reviewers' and editor's belief in its value as consistent with the Journal's motto: 
"Our troubled planet can no longer afford the luxury of pursuits confined to an ivory tower. Scholarship has to prove its worth, not in its own terms, but by service to the nation and the world."-Oscar Handlin

Thanks are extended to Michael Grant, Timothy Grzesiakowski, Todd Litman, William Menczer, and Phillip Winters for review and comments on this paper.

\section{About the Authors}

STUART BAKER (Stuart@enviro-urban.org) has worked promoting transportation alternatives since 1995 . He now assists companies providing transit benefits and manages a foundation supporting urban-based environmental projects. As Vice President of Marketing for Accor Services USA and President of Commuter Benefits Management, Inc., he developed and marketed transit benefit solutions for Fortune 500 companies. Previously, he managed the transit benefit plan for 2500 City and County of San Francisco employees, trained Employee Transportation Coordinators and managed programs at the Bay Area's regional rideshare organization.

DAVID JUDD (djudd601@gmail.com) has expertise in transportation market development, with focus on employers, private sector service providers, and vendors. As Vice President, Business Development of Accor Services USA /Commuter Check, he devised new products and services and implemented strategies to increase visibility. Other experience includes intelligent transportation systems and incident, special event, and emergency management. He was Vice President of Commuter Check Services Corp., Marketing Manager at TransitCenter in New York City, Contracts Administrator for Edison Parking Corp., and manager of NJ Transit's Rail Station Leasing Program. He has a BA in Urban Affairs and an MPA from George Washington University.

RichaRd L. ORAM (Richard@enviro-urban.org) has a 35-year career in the urban transit industry, focused on fares and revenue strategies, traffic mitigation, market research, and strategies for involving the business community in urban transport innovations. He worked for the Urban Mass Transit Administration (now Federal Transit Administration) in the 1970s, with local transit agencies, and as a consultant. He founded Commuter Check Services Corp. in 1990. He currently chairs an international foundation, The Fund for the Environment and Urban Life (www.enviro-urban. org). He has economics and urban planning degrees from Lehigh University and the London School of Economics and Political Science, and received an Outstanding Public Service Award from the U.S. Department of Transportation in 1982. 